\title{
A comprehensive review of Energy Internet: basic concept, operation and planning methods, and research prospects
}

\author{
Yijia CAO ${ }^{1}$, Qiang $\mathrm{LI}^{1}$, Yi TAN ${ }^{1}$, Yong $\mathrm{LI}^{1}$, Yuanyang CHEN ${ }^{2}$, \\ $\mathrm{Xia} \mathrm{SHAO}^{1}$, Yao ZOU ${ }^{1}$
}

\begin{abstract}
With the intensifying energy crisis and environmental pollution, the Energy Internet and corresponding patterns of energy use have been attracting more and more attention. In this paper, the basic concept and characteristics of the Energy Internet are summarized, and its basic structural framework is analyzed in detail. On this basis, couplings between the electric power system and other systems such as the cooling and heating system, the natural gas system, and the traffic system are analyzed, and the operation and planning of integrated energy systems in both deterministic and uncertain environments are comprehensively reviewed. Finally, the research prospects and
\end{abstract}

CrossCheck date: 19 November 2017

Received: 14 July 2016/Accepted: 19 November 2017/Published online: 13 December 2017

(C) The Author(s) 2017. This article is an open access publication

$\triangle$ Yi TAN

yitan@hnu.edu.cn

Yijia CAO

yjcao@hnu.edu.cn

Qiang LI

liqiang0419@foxmail.com

Yong LI

liyong1881@163.com

Yuanyang CHEN

hndlcyy@qq.com

Xia SHAO

syice2003@163.com

Yao ZOU

379712700@qq.com

1 College of Electrical and Information Engineering, Hunan University, Changsha 410082, China

2 State Grid Hunan Electric Power Company Limited, Changsha, China main technical challenges of the Energy Internet are discussed.

Keywords Energy Internet, Combined cooling heating and power (CCHP), Integrated natural gas and electric power system, Integrated electric and traffic system

\section{Introduction}

In the 21th Century, traditional patterns of energy use based on centralized conversion of fossil energy have been facing many challenges such as the energy crisis and environmental pollution [1]. It has been recognized that solutions mainly include two aspects, i.e., developing renewable energy sources (e.g., solar, wind and biological energy) and improving the efficiency of energy use. As shown in the "EU Energy Road Map 2050" [2], it was forecast that more than $55 \%$ of global energy demand is expected to be satisfied by renewable energy sources by 2050. In such an era, a sustainable energy supply system with high energy efficiency is required. Therefore, it is urgent to create an integrated energy system to optimally coordinate various renewable energy sources and different energy systems [3]. Combining this context with Internet technology, Jeremy Rifkin proposed the vision of the Energy Internet (EI) in 2011, which can make full use of distributed renewable energy, and improve energy efficiency and electric power system reliability [4]. The ultimate goal of the Energy Internet is to realize distributed and renewable energy systems [5]. The concept, framework and composition of the Energy Internet have been continuously developed since then.

Compared with the existing energy system, the Energy Internet can be regarded as a peer-interconnected sharing 
network with advanced power electronic technology, newenergy technology and information technology. With those technologies, the coordination and two-way energy and information flow can be realized [6]. Also, the Energy Internet can be interpreted as an integrated energy supply system, i.e., the electric power system tightly coupled with other energy networks such as the natural gas network, the traffic network and the information network [7, 8], as shown in Fig. 1. In this figure, the electric power system is the conversion hub between various forms of energy and is the core of the EI, since it owns significant advantages in energy transmission efficiency and it carries the most convenient form of energy for end-users. In the Energy Internet, different energy systems are coupled through energy transformation devices (e.g., micro-turbine, electric vehicle (EV), power to gas $(\mathrm{P} 2 \mathrm{G})$, or vehicle to grid (V2G)). For instance, using $\mathrm{P} 2 \mathrm{G}$ technology, surplus renewable energy can be transformed into methane, and then used to supply natural gas load [9].

In contrast with traditional energy supply systems, the EI generally has such characteristics as utilizing renewable energy [10], plug and play (PnP) of distributed devices and EVs [11], and balancing energy supply and demand via wide-area energy sharing, energy router and efficient information management [12, 13]. Therefore, many developed countries have carried out related research on the EI. In the US, the Future Renewable Electric Energy Delivery and Management research center was built to develop a high-efficiency distribution system with high penetration with $\mathrm{PnP}$ of distributed generators (DGs) $[14,15]$. In Germany, the "E-Energy" project was proposed, which aimed at establishing an intelligent energy system based on information and communication technology $[16,17]$. In Switzerland, the Vision of Future Energy Networks project proposed two key elements of the EI: a hybrid energy hub and an energy interconnector [18, 19]. However, research about EI exploration and practice is still in the preliminary stage, and a deep and comprehensive survey on the EI is needed.

In this paper, we will first give a comprehensive review of the concept, characteristics, framework and development of the Energy Internet. Then, Sects. 2, 3 and 4 analyze different EI systems, i.e., a combined cooling heating and power system, an integrated natural gas and electric power system, and an integrated electric and traffic system respectively. In those sections, state-of-the-art research on operation and planning methods for such integrated energy systems are reviewed from the perspectives of deterministic environment and uncertain environment. Finally, the research prospects and main technical challenges of the Energy Internet are discussed in Sect. 5.

\section{Operation and planning optimization of CCHP system}

\subsection{Combined cooling heating and power system}

As an important type of distributed generation, combined heat and power (CHP) plants can supply heat energy and electric energy at the same time. Compared with separate generation of heat and electric power, the fuel economy and overall efficiency of CHP are higher [20]. As refrigeration technology has advanced in recent years,

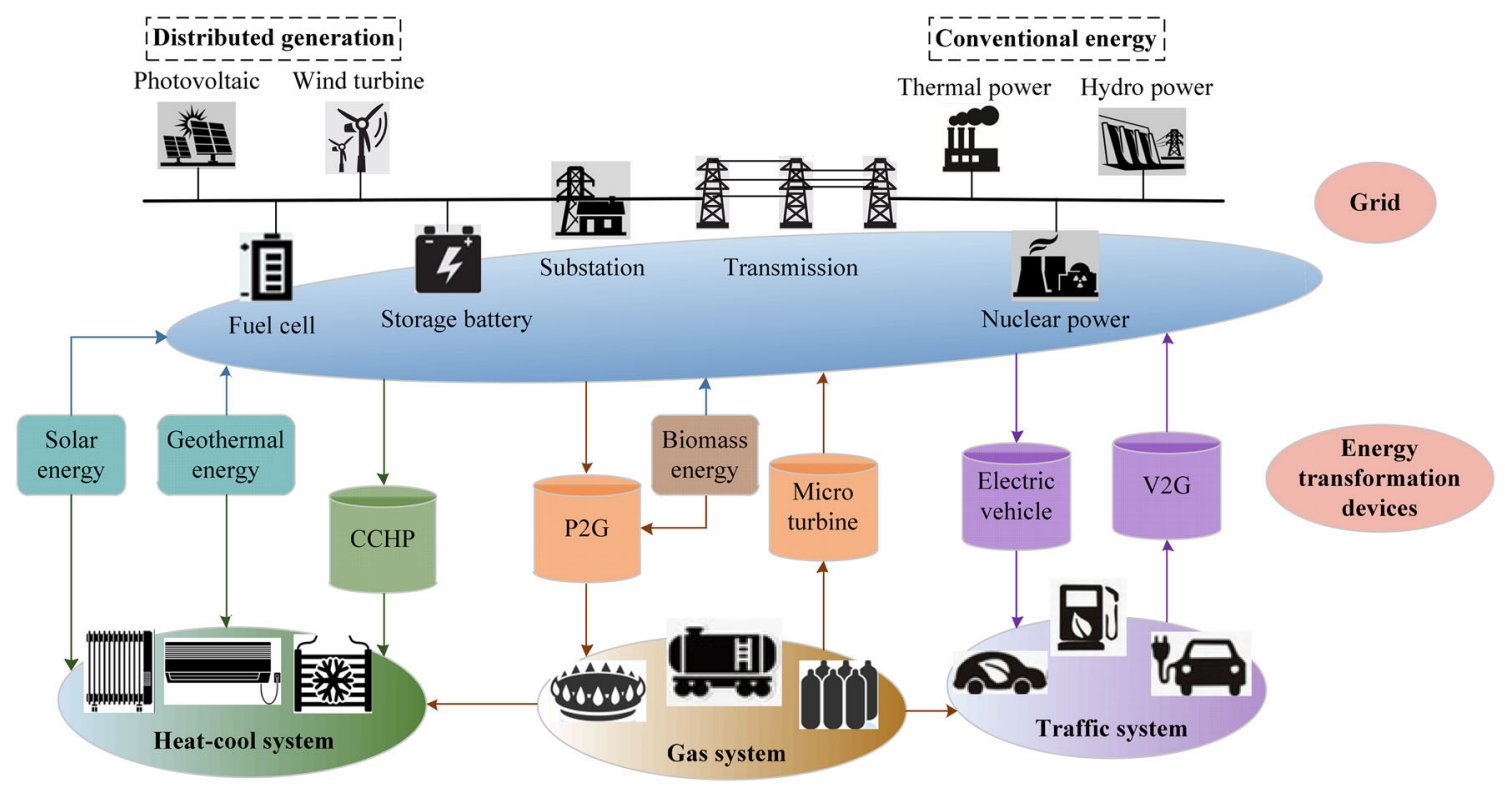

Fig. 1 Basic structural framework of Energy Internet 
combined cooling heating and power (CCHP) plants have become one of the most promising, practical and flexible resources in electric power systems [21]. A CCHP system includes electric power generation, heating and cooling [22], and the production of heating, cooling and electric energy can be balanced with load requirements to improve the overall energy efficiency from $40 \%$ to $70 \%-90 \%$ [23]. In addition, a CCHP system has the advantages of emission reduction and cascaded energy use.

As shown in Fig. 2, a CCHP system generates electricity by means of a micro-turbine (MT) or a reciprocating engine. It recycles waste heat through the heat recovery unit and bromide absorption refrigerator; then the waste heat is used to satisfy thermal demands.

Mathematically, the MT-based CCHP model can be formulated as follows [24]:

$$
\left\{\begin{array}{l}
Q_{M T}=P_{e}\left(1-\eta_{e}-\eta_{1}\right) / \eta_{e} \\
Q_{h e}=Q_{M T} K_{h e} \\
Q_{c o}=Q_{M T} K_{c o}
\end{array}\right.
$$

where $Q_{M T}, P_{e}, \eta_{e}$ and $\eta_{1}$ represent heat discharge allowance, output power, generating efficiency and heat loss coefficient of the MT, respectively; $Q_{h e}, Q_{c o}$ are the total heating and cooling generation; and $K_{h e}, K_{c o}$ are equivalent thermal coefficient and refrigeration coefficient considering losses and the typical average daily temperature.

\subsection{Objectives and constraints}

The integration of CCHP into electric power systems has significant effects on branch power flow and nodal voltages. The conversion of heat energy is tightly coupled with electric power generation in a CCHP system, thus affecting the electric power balance. Therefore, much research has addressed electric power system optimization with CCHP.

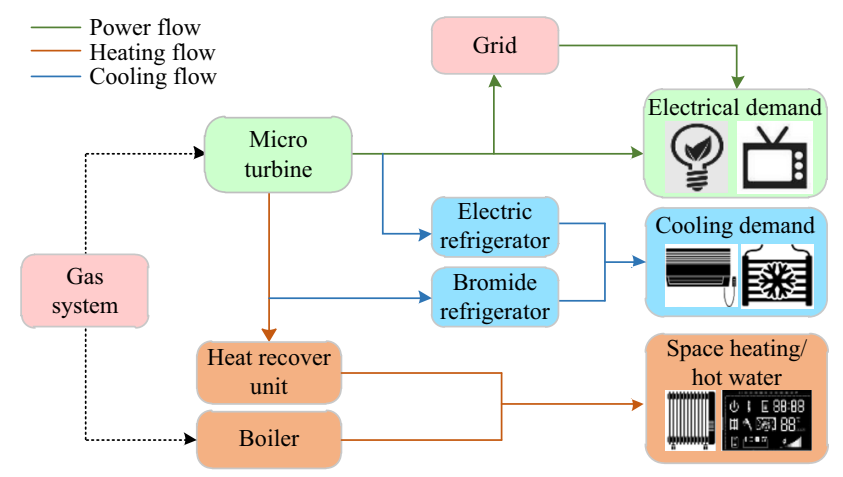

Fig. 2 Configuration of CCHP system with indicated electrical and thermal power flow

\subsubsection{Objective function}

As shown in Table 1, considering different factors, the objective function of CCHP optimization problems generally includes the following aspects:

1) Maximizing the economic benefits. This requires minimizing the power generation costs and satisfying the energy demands in the most economical way [24-29]. In general, the significant costs are the power generation costs of DGs and conventional energy sources, the operational cost of the MT, and the costs of power exchange between the CCHP system and the electric power system.

2) Maximizing the overall benefits including the economic benefits, the environmental benefits, and the heating and refrigeration benefits [24]. The use of fossil fuels can produce greenhouse gases and harmful gases (e.g. nitrogen oxides, sulfur dioxide), thus it is necessary to calculate pollution costs when considering environmental factors. Moreover, since heating and refrigeration can make profits, the overall benefits should consider the heating and refrigeration profits. The objective function can be formulated as:

$C=C_{0}+C_{p o}-C_{h e}-C_{c o}$

where $C_{0}$ is the total cost including power generation costs, operational costs and power exchange costs; $C_{p o}$ is the total pollution cost of different energy sources according to the formulae that can be found in [28-30]; and $C_{h e}, C_{c o}$ are the heating and refrigeration profits, calculated based on the heating/cooling power and unit price.

\subsubsection{Constraints}

Since CCHP system is a power plant combining cooling, heating and electric generation, the constraints applying to electric power system optimization with CCHP generally includes the following aspects:

1) Electric power system constraints. They can be derived from the constraints in typical electric power system optimization models, including voltage constraints, current constraints, electric power balance constraints, maximum installed capacity constraints and active power constraints of DGs [31, 32].

2) Cooling and heating system constraints. They mainly refer to the heating/cooling load balance constraints and the operational constraints of heating/cooling units $[32,33]$. The latter generally comprises the generation, transmission and storage constraints of the cooling and heating system, e.g., the heat constraints of the gas 
Table 1 Summary of objective functions and constraints for integrated energy systems

\begin{tabular}{|c|c|c|c|}
\hline \multirow[t]{2}{*}{ System } & \multirow[t]{2}{*}{ Major objective functions } & \multicolumn{2}{|l|}{ Major constraints } \\
\hline & & Other system constraints & $\begin{array}{l}\text { Electric power } \\
\text { system constraints }\end{array}$ \\
\hline CCHP-related system & $\begin{array}{l}\text { Economic benefits } \\
\text { Overall benefits including economic benefits, } \\
\text { environmental benefits, and heating and refrigeration } \\
\text { benefits }\end{array}$ & $\begin{array}{l}\text { Heating/cooling load balance } \\
\text { constraints } \\
\text { Heat constraints of the gas } \\
\text { boiler } \\
\text { Output constraints of bromide } \\
\text { refrigerator } \\
\text { Heating/cooling storage } \\
\text { constraints } \\
\text { Capacity constraints of } \\
\text { heating/cooling transmission } \\
\text { lines }\end{array}$ & \\
\hline $\begin{array}{l}\text { Integrated natural gas and } \\
\text { electric power system }\end{array}$ & $\begin{array}{l}\text { Capital benefits } \\
\text { Energy benefits }\end{array}$ & $\begin{array}{l}\text { Gas flow balance constraint } \\
\text { Gas transmission constraints } \\
\text { Natural gas capacity constraints } \\
\text { P2G constraints }\end{array}$ & $\begin{array}{l}\text { Electric power } \\
\text { balance } \\
\text { constraints } \\
\text { Voltage constraint } \\
\text { Current constraint } \\
\text { Electric generator } \\
\text { constraints }\end{array}$ \\
\hline $\begin{array}{l}\text { Integrated electric and } \\
\text { traffic system }\end{array}$ & $\begin{array}{l}\text { Stabilize the fluctuations of electric power system } \\
\text { Optimal planning of charging stations }\end{array}$ & $\begin{array}{l}\text { Capacity constraint of charging } \\
\text { lines and substations } \\
\text { Constraints of charging devices } \\
\text { EVs batteries capacity } \\
\text { constraints } \\
\text { Charging power constraints of } \\
\text { EVs } \\
\text { V2G power constraints } \\
\text { Traffic network constraints }\end{array}$ & \\
\hline
\end{tabular}

boiler, the output constraints of the bromide refrigerator, heating/cooling storage constraints, and the capacity constraints of heating/cooling transmission lines.

\subsection{Planning and scheduling methods}

Since uncertainties exist in operation, e.g. the uncertainties of load and renewable power output, the operation and planning of electric power systems with CCHP can be divided into two parts.

\subsubsection{Deterministic methods}

In deterministic approaches, uncertainties are neglected, and planning and scheduling algorithms are relatively simple. Linear programming (LP) $[34,35]$, nonlinear programming (NLP) and mixed integer linear programming (MILP) $[36,37]$ have been widely applied to the CCHP optimization problem. Rong et al. modeled the hourly trigeneration problem as a LP model considering the joint characteristic of three energy components and proposed the Tri-Commodity Simplex (TCS) algorithm to minimize the total production and purchasing costs, as well as $\mathrm{CO}_{2}$ emissions costs [34]. Although LP offers significant advantages, it requires linearization of non-linear constraints in systems with CCHP, which introduces calculation errors. Thus, mathematically, NLP seems to be a more rigorous and accurate method, especially when considering the logistical constraints for the equipment [38, 39]. A notable example is [38], which proposed a non-linear cost-minimization model to obtain the optimal operational strategy for a CCHP system. These deterministic approaches provide important insight into the operation optimization of electric power systems with CCHP, however, they cannot deal with uncertainties such as load uncertainties.

\subsubsection{Methods for handling uncertainties}

The uncertain parameters can be generally classified into two categories including technical parameters and 
economical parameters [40]. Specifically, in the operation and planning of a CCHP system, the former includes outages of lines and generators and uncertain demand and generation, and the latter includes the uncertainties of fuel prices and environmental policies. Due to the complexity of optimization under uncertainties, it is necessary to adopt more effective methods to analyze the operation and planning of a CCHP system [41]. Up until now, state-ofthe-art methods can be generally categorized into three main classes as follows.

a) Probabilistic methods

In probabilistic methods, the random variables are modeled by probability density functions, and applicable methods include the chance-constrained programming method and the two-stage stochastic programming method [42]. For chance-constrained optimization, the constraints are formulated in probabilistic terms and thus decision-makers can know the likelihood of meeting the constraints [43]. In [44], Niknam et al. proposed chance constrained programming to handle multi-objective economic load dispatch using a jointly distributed random variables method. For the two-stage stochastic programming method, the effects of decisions after uncertain variables are realized can be well represented. A specific case in [45] shows that this method could handle uncertainties in the optimal sizing of cogeneration systems, where it firstly calculates the optimal capacities of CHP and boiler before uncertainties such as errors of the electrical and thermal loads are realized, and secondly determines the operational strategy by using realized scenarios.

b) Fuzzy methods

In fuzzy analysis methods, the uncertain parameters are described by using the membership function, and fuzzy membership can be obtained by subjective investigation $[46,47]$. These methods are commonly used to quantify uncertain factors such as social and other qualitative indices, for which probability distributions are not available. For instance, Jing et al. [48] proposed Fuzzy Multi-Criteria Decision Making and evaluated the complex relationship between CCHP systems and society, economy, and the environment. Fuzzy set theory has also been widely applied to deal with insufficient data and uncertain load demand [49]. In [50], a multiobjective model based on fuzzy programming was proposed to minimize cost and maximize demand satisfaction. Combined uncertainties of price and load have been dealt with using fuzzy programming [51, 52]. In [47], uncertainties associated with electrical demand, thermal demand, and the prices of electricity and natural gas were modeled by using fuzzy sets as a percentage change from their nominal values. Then a hybrid optimization method was used to determine the desired optimal CCHP configuration.

c) Robust optimization

Robust optimization uses intervals to model uncertain variables and thus does not need accurate probability distribution functions and fuzzy membership functions. In [53], a model based on robust optimization was presented to consider uncertain load and price in the context of Energy Analysis-Based Optimization of Trigeneration (EABOT). The goal of [53] was to achieve optimal operation with high probability. However, up until now, research in this field is still limited.

In summary, useful research ideas have been presented for CCHP-related optimization. With the increasing numbers of highly-coupled distributed devices, more focus should be given on different random and fuzzy factors in electric power systems. Although a hybrid "possibilistic" and probabilistic model has been proposed [54], most of the current research adopts a probabilistic model or fuzzy model to deal with all uncertainties, calling for deep and comprehensive research.

\section{Coupling of electric power system and natural gas system}

\subsection{Integrated natural gas and electric power system}

An integrated gas and electricity network is one of the most important energy systems in economic and environmental terms. The coordinated operation and planning of the gas network, electricity generators, and transmission and distribution networks can reduce energy consumption and lead to an optimal structure for the combined systems. Up until now, a large number of studies have been done to analyze the interaction of the gas and electric networks in joint planning. For example, the study towards coordinated planning has been undertaken in the United States [55, 56], and some common problems related to the development of natural gas and electricity networks (operation costs, network expansion costs, optimal placement of gas-fired generation plants) have been analyzed in Europe [57]. Although the research in this area starts late in China, related concepts and models have been already proposed, such as a smart energy network based on multiple energy sources [58].

With the development of shale gas reserves and $\mathrm{P} 2 \mathrm{G}$ technologies $[59,60]$, and the potential roles of gas in clean energy systems, the proportion of gas energy and gas-fired power generation in energy systems has seen significant growth, and the power network and gas network become 


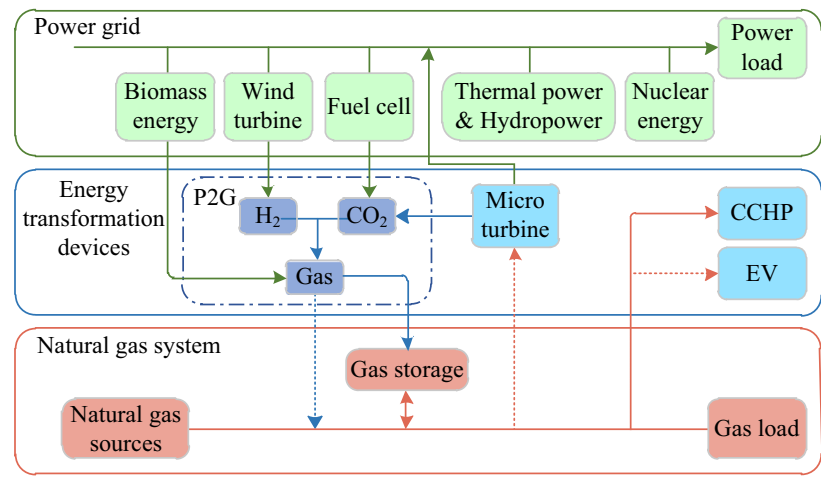

Fig. 3 Configuration of an integrated natural gas and electric power system indicating electrical and gas power flow

more tightly coupled. Referring to [9], the surplus output of renewable energy sources can be transformed into methane using P2G technology, and then used to supply natural gas load, as shown in Fig. 3. This achieves bidirectional energy flow between the electric power system and the natural gas system. Since natural gas is easy to store, the large-scale storage of renewable energy can be realized.

\subsection{Objectives and constraints}

\subsubsection{Objective function}

Generally, the objective function includes the following aspects.

1) Maximizing the capital benefits. This is the main research direction for the coordinated planning of natural gas and electric power systems. It can minimize the total cost of two energy systems, which include investment costs and operational costs of all generator units and natural gas production, storage, and transportation [61, 62].

2) Maximizing the energy benefits. As the energy supply network of the EI, minimizing losses in the natural gas system and the electricity system is also an important optimization objective in their coordinated planning [63].

\subsubsection{Constraints}

In the integrated natural gas and electric power system, besides the electric power system constraints described in Sect. 2.2.2, the following constraints related to natural gas systems are considered.

1) Gas flow balance constraint [66, 67]. This constraint requires that the sum of gas production is equal to the total consumption including any losses.
2) Gas transmission constraints, mainly referring to the strength and stability constraints for pipelines and their gas flow constraints [64].

3) Natural gas capacity constraints, i.e., the capacity constraints of gas production units and gas storage [62].

4) P2G constraints, mainly including the cost and technical constraints of $\mathrm{P} 2 \mathrm{G}$ facilities. The former comprises investment costs, operational costs and maintenance costs of P2G. The latter mainly includes the constraints related to carbon dioxide and hydrogen, such as hydrogen storage constraints and carbon dioxide capture constraints. Although P2G technology is costly at present, it may become one of the cheapest ways to produce energy in the future [65].

\subsection{Planning and scheduling methods}

\subsubsection{Deterministic methods}

In the field of deterministic optimization, state-of-the-art models are mainly aimed at minimizing the investment and operational costs and optimizing the capacity and location of new facilities. Different methods and models have been presented based on MILP [66-69]. For instance, a longterm and multistage model for supply and interconnection expansion planning of integrated electricity and natural gas networks was proposed in [67] to determine the optimal location of new facilities; Unsihuay et al. presented another integrated planning approach for hybrid power and natural gas systems [69]; and an energy hub and coupling matrix were proposed in [70-72] to achieve the optimal energy conversion between gas and electricity. The goal was to minimize the operational costs of the two networks. Particularly, this method can be used for more than two energy systems and a notable example is shown in [72], in which optimal operation of multi-energy systems was investigated through the coupling matrix method.

\subsubsection{Methods for handling uncertainties}

Besides the uncertain factors of the electric power system, the uncertainties of the integrated natural gas and electric power system also include the failure of pipelines, gas production and gas demand, and the gas price. As shown in Table 2, the operation and planning of this integrated system is approached mainly by two methods. The first one is the probabilistic method. For instance, a two-stage stochastic programming method was proposed in [73] for optimal security-constrained unit commitment in hybrid hydro and natural gas systems. Also, this method was used in [74] to evaluate the effect of emergencies in integrated power and natural gas system. Sun et al. adopted a three-point estimate 
Table 2 Summaries of the methods in the integrated energy systems

\begin{tabular}{lllll}
\hline System & Deterministic method & \multicolumn{2}{l}{ Major methods for handling uncertainties } \\
\cline { 3 - 5 } & & & Probabilistic methods & \multicolumn{2}{l}{ Non-probabilistic methods } \\
\cline { 3 - 5 } & & & Fuzzy method & Interval based method \\
\hline CCHP-related system & {$[34-39]$} & {$[42-45]$} & {$[46-52]$} & {$[53]$} \\
Integrated natural gas and electric power system & {$[66-72]$} & {$[73-75]$} & 1 & {$[76]$} \\
Integrated electric and traffic system & - & {$[91-95]$} & {$[96,97]$} & {$[98,99]$} \\
\hline
\end{tabular}

method based on the Nataf transformation to tackle the uncertainty of and the correlation between different energy loads to minimize total cost [75]. The other one is the interval optimization based method. In this context, Bai et al. [76] proposed an operating strategy based on interval optimization for integrated natural gas and electric power systems to improve the overall system operation and optimize the energy flow. In the proposed model, wind uncertainty and demand response were also considered and wind power uncertainty was represented using intervals.

Since most optimization models just take the sum of investment costs and operation costs of the two systems as the objective function, and rarely consider the stability of the integrated system, their optimization results are not comprehensive enough to assure secure as well as economic operation.

\section{Operation and planning of integrated electric and traffic system}

\subsection{Integrated electric and traffic system}

EVs and charging facilities are becoming an important part of city planning and infrastructure in many countries, and the plug-and-play of EVs has a significant impact on the Energy Internet. Taking EVs and charging facilities (e.g., charging piles and charging stations) as the bridge, the interaction between the electric distribution system and the traffic system is deepening constantly. On the one hand, EVs in aggregation can act as large-scale distributed energy storage devices to contribute to system regulation such as stabilizing the fluctuations of DGs [77] and shifting peak load [78], and on the other hand, the randomness of EV charging can compromise the stability of the electric power system [79, 80].

Up to now, many studies have been carried out and different mathematical models have been developed for the operation and planning of integrated electric and traffic systems. This research mainly focus on two major aspects. One is the coordinated operation of EVs and the power grid. It generally includes investigating the impact of EVs on the electric power system, the optimal scheduling of EV charging, stabilizing the fluctuations of DGs, peak demand and frequency control through EVs, and so on [78-80]. The other aspect is the coordinated planning of integrated electric and traffic systems, which mainly refers to planning of charging stations [81-84] and power system planning with EVs and charging stations [85-88]. Since the optimal location and sizing of charging stations could minimize the total costs of charging stations while satisfying the charging demands of EVs and supporting the optimal distribution network expansion planning, it could be one of the most important research topics to be studied in depth for the EI.

\subsection{Objectives and constraints}

\subsubsection{Objective function}

As discussed above, different models have been established for the operation and planning of integrated electric and traffic systems, and the objective functions generally aim to achieve:

1) Stabilizing the fluctuations of the electric power system [80]. This mainly refers to stabilizing the renewable power generation fluctuations and load fluctuation. Although the randomness of EV charging can compromise the stability of electric power system, the aggregated impact of EVs can contribute to system regulation as large-scale distributed energy storage to stabilize the fluctuations of DGs and shift peak load, using V2G technology.

2) Optimal planning of charging stations [83, 84]. This refers to the optimal locating and sizing of charging stations and includes both the total costs and the social benefits. Therefore, the objective function includes the investment costs, operational costs and maintenance costs of charging stations, the cost of network losses, and charging costs to users. In general, it can be formulated as:

$C_{A}=C_{1}+C_{2}+C_{3}+C_{4}$

where $C_{1}$ is the investment cost of charging stations; $C_{2}$ is the operational costs and maintenance costs of 
charging stations, including the staff salaries, equipment depreciation costs, and equipment maintenance costs; $C_{3}$ is the network loss costs; and $C_{4}$ is the charging costs to users, which can be measured by the journey to charging stations and the waiting time at them. It measures the service capacity of charging stations, and is influenced by the traffic network and traffic flows.

\subsubsection{Constraints}

Corresponding to the objective functions mentioned above, the integrated electric and traffic system constraints include electric power system constraints (similarly to Sect. 2.2.2) and traffic-related system constraints, with the latter including:

1) Charging station constraints. These include the capacity constraint of charging lines, the capacity constraint of substations, and the constraints of charging devices [84].

2) Electric vehicle constraints. These include the capacity constraint of EV batteries, the charging power constraints of EVs, and the V2G power constraints [89, 90].

3) Traffic network constraints. The traffic system and the electric power system have complex mutual influence. Traffic flows can affect the planning of charging stations and the construction of the power system. In turn, the distribution of charging stations also influences traffic flows. Traffic flows are also greatly affected by user behavior and charging strategies. Therefore, the operation and planning of integrated electric and traffic systems is mainly constrained by traffic flows, traffic congestion levels, the road conditions and the potential to extend the road network, user behavior, weather conditions, and other factors [84, 85].

\subsection{Mathematical methods}

The randomness of $\mathrm{EV}$ charging behavior introduces inherent uncertainty to an integrated electric and traffic system, and deterministic planning methods cannot be used. Methods for handling uncertainties in an integrated electric and traffic system can be classified into two major categories as follows.

\subsubsection{Probabilistic methods}

Probabilistic methods have been widely used in optimizing integrated electric and traffic systems, such as the two-stage optimization method [91, 92], the chance constrained optimization method [93, 94], and the point estimate method [95]. For instance, a two-stage optimization method was proposed in [91] to minimize the energy losses in a microgrid with different penetrations of hybrid EVs (HEVs). In the first stage, a convex quadratic objective function was established for active power management of HEVs, and the daily energy requirement of HEVs was calculated from a stochastic model of their owners' behavior. Then, the second stage managed reactive power of HEVs when employed as capacitors. In addition, Waqar et al. presented a multi-objective chance constrained programming model to investigate the economic implications of V2G on microgrids containing renewable energy sources and to optimize their operational planning [93].

\subsubsection{Non-probabilistic methods}

Fuzzy logic methods are often used to account for uncertain factors when determining the location of charging facilities and strategies for energy management [96, 97]. In [96], the fuzzy TOPSIS method was applied to select optimal locations for EV charging stations. Using multi-criteria decision making, [96] established an evaluation index system for charging station site selection, which includes environmental, economic and social criteria.

Interval-based methods also play an important role in the optimization and scheduling of integrated electric and traffic systems. For instance, a new method based on robust optimization was proposed to plan sustainable integration of HEVs into the electric grid in [98]. Interval power flow analysis was used in distribution system optimization to achieve the dispatch of each electric vehicle charging based on the statistical model [99]. In that work, a cluster-based strategy was proposed for the scheduling of EV charging, in which uncertainties such as charging power were modelled by intervals.

Several analysis methods have been developed for planning charging stations and for planning distribution systems with charging stations. However, they are usually based on existing road networks and traffic flows, which may not be sufficient for practical application. Although the traffic flow, traffic density and road network models have been proposed in [84, 85], additional research is needed on implications for road network planning, the impact of weather conditions, and other issues.

\section{Research prospects}

Building on information technology trends such as the Internet of Things (IoT), Big Data, cloud computing, realtime user interaction, etc., the Energy Internet represents the evolution of an integrated energy system with diverse 
structure, clean energy sources, electrified consumption and intelligent operation. Although the Energy Internet is promising and some of its operation and planning problems have already been investigated, there are still many crucial technical obstacles to be resolved, such as developing energy storage devices of large capacity and low loss, or an energy transmission system of high efficiency and low cost, or energy conversion and transformation components with the intelligence and flexibility of information system components [100-106].

In view of different technical issues and trends relating to the EI, the main directions of future research should be as follows.

1) Optimal coupling of multi-energy systems. The coordinated coupling between subsystems of the EI allows the synergy of different energy flows to economically and securely deliver heating, cooling, gas, traffic, and electric energy. Therefore, high-efficiency energy transformation devices and the interaction pathways they enable between different energy systems should be studied in depth, especially low-cost P2G technologies and impacts. Coordinated operation and planning models for multi-system coupling should be approached through quantitative analysis of energy balance, environmental impacts, and other societal benefits and costs. In this context, using realistic energy network topologies, the role of different subsystems and their uncertainties in corresponding interaction models among multiple systems should be evaluated; e.g. renewable DGs, traffic flow, weather conditions, energy markets and demand response.

2) Advanced information and communication systems for secure operation of the Energy Internet. For real-time optimization of integrated energy systems and for coordinating large numbers of distributed devices, a large computing capacity is needed to deal with huge amounts of diverse energy data. Thus, it is important to develop advanced information and communication technology (ICT) for application to integrated energy systems, e.g. Big Data, IoT, cloud computing, cloud storage, and block chaining for the Energy Internet. Since energy flow and information flow are tightly coupled, Energy Internet cyber systems should be further investigated to overcome technical obstacles in data association, information collection and secure dispatch, and real-time control in multiple energy markets.

3) Unified network codes and coordinated national management and promotion policies for a global cyberenergy system. In an open and competitive market, it is crucial to establish and develop a secure and highly efficient global Energy Internet. Therefore, international cooperation is required to unify network codes, planning standards, energy transformation devices and information system interfaces. The same cooperative process should also coordinate different national firewalls, energy laws, management systems, and development policies. Although the ideal of global energy interconnection has been established [107], more work is needed to strengthen international collaboration towards the Energy Internet. Because existing studies about the Energy Internet are at the stage of theoretical research, corresponding engineering standards for a global Energy Internet are necessary for further progress.

4) Demonstration projects of new functionality for the large-scale EI. Some practical demonstration projects have been already built to validate the feasibility of the Energy Internet, especially relating to the integration of DGs and EVs. For example, the Shenzhuang Industrial Zone distributed energy station in Shanghai [108] has been built as a micro-EI to provide heating, cooling and electricity for the industrial zone. The Tianjin Eco-City and Smart Grid Demonstration Project was established by State Grid Corp. of China in 2014 [109], in which the interconnection and sharing of energy and information has been achieved across DGs, CCHP, energy storage, EVs, demand response, an information network, and a data platform. These projects demonstrate the feasibility of developing the Energy Internet and provide a practical foundation of experience. However, they are microEIs based on distributed energy. In the future, using information technologies such as Big Data and cloud computing, some demonstration projects are needed to promote the development of the large-scale Energy Internet.

\section{Conclusion}

The supply structure is one of the most vital elements that influence the energy systems and environment. Through the continuous development of the Energy Internet, a convergence of distributed energy sources, diverse forms of energy including gas, heating, cooling, and electricity, and supported by the data internet, will lead to a sustainable multi-energy system. Based on the analysis of an Energy Internet framework, this paper focuses on three examples of coupled energy systems, and analyzes state-ofthe-art operation and planning methods applicable to each. Four main directions of further research prospect address the key challenges of optimal coupling, cyber systems, unified standards, and large-scale demonstrations. Though 
research into the Energy Internet has only just begun, it is one of the most important topics in energy nowadays and worthwhile for the research community to pursue.

Acknowledgements This work was supported in part by the National Natural Science Foundation of China (No. 51520105011), in part by the Key S\&T Special Project of Hunan Province of China (No. 2015GK1002) and in part by the Science and Technology Project of Hunan Province of China (No. 2015WK3002).

Open Access This article is distributed under the terms of the Creative Commons Attribution 4.0 International License (http:// creativecommons.org/licenses/by/4.0/), which permits unrestricted use, distribution, and reproduction in any medium, provided you give appropriate credit to the original author(s) and the source, provide a link to the Creative Commons license, and indicate if changes were made.

\section{References}

[1] U.S. Department of Energy (2009) Smart grid system report. USA, July 2009

[2] Michael H, Andreas L (2013) The EU decarbonisation roadmap 2050-what way to walk? Energy Policy 55:190-207

[3] Quelhas A, Gil E, McCalley JD et al (2007) A multiperiod generalized network flow model of the U.S. integrated energy system: part I-model description. IEEE Trans Power Syst 22(2):829-836

[4] Rifkin J (2011) The third industrial revolution: how lateral power is transforming energy, the economy, and the world. Palgrave MacMillan, New York

[5] Tsoukalas LH, Gao R (2008) From smart grids to an energy internet: Assumptions, architectures and requirements. In: Proceedings of the third international conference on electric utility deregulation and restructuring and power technologies, Nanjing, China, 6-9 April 2008, pp 94-98

[6] Dong ZY, Zhao JH, Wen FS et al (2014) From smart grid to energy internet: basic concept and research framework. Autom Electr Power Syst 38(15):1-11

[7] Li FX, Qiao W, Sun HB et al (2010) Smart transmission grid: vision and framework. IEEE Trans Smart Grid 1(2):168-177

[8] Sun QY, Teng F, Zhang HG et al (2015) Construction of dynamic coordinated optimization control system for Energy Internet. Proc CSEE 35(14):3667-3677

[9] Clegg S, Mancarella P (2015) Integrated modeling and assessment of the operational impact of power-to-gas (P2G) on electrical and gas transmission networks. IEEE Trans Sustain Energy 6(4):1234-1244

[10] Yu SH, Sun Y, Niu XN et al (2010) Energy internet system based on distributed renewable energy generation. Electr Power Autom Equip 30(5):104-108

[11] Zhou XS, Wang FZ, Ma YJ (2015) An overview on energy internet. In: Proceedings of IEEE international conference on mechatronics and automation (ICMA), Beijing, China, 2-5 Aug 2015, pp 126-131

[12] Cao JW, Yang MB (2013) Energy internet-towards smart grid 2.0. In: Proceedings of the fourth international conference on networking and distributed computing (ICNDC), Los Angeles, CA, USA, 21-24 Dec 2013, pp 105-110

[13] Xu Y, Zhang JH, Wang WY et al (2011) Energy router: Architectures and functionalities toward Energy Internet. In:
Proceedings of IEEE international conference on smart grid communications, Brussels, Belgium, 17-20 Oct 2011, pp 31-36

[14] Huang AQ, Crow ML, Heydt GT et al (2011) The future renewable electric energy delivery and management (FREEDM) system: the energy internet. Proc IEEE 99(1):133-148

[15] Huang A (2010) FREEDM system-a vision for the future grid. In: Proceedings of IEEE power and energy society general meeting, Providence, RI, USA, 25-29 July 2010, pp 1-4

[16] European Commission (2012) Recorded conference "Mission growth: Europe at the lead of the new industrial revolution". http://ec.europa.eu/avservices/video/player.cfm?ref=85716. Accessed 29 May 2012

[17] E-energy (2013) Federal ministry of economics and energy of Germany. http://www.e-energy.de/en/index.php. Accessed 26 June 2013

[18] Geidl M, Favre-Perrod P, Klöckl B et al (2006) A greenfield approach for future power systems. CIGRE sessions 41, Paris, France

[19] Shen Z, Liu ZM, Baran M (2012) Power management strategies for the green hub. In: Proceedings of IEEE power and energy society general meeting, San Diego, CA, USA, 22-26 July 2012, pp 1-4

[20] Jablko R, Saniter C, Hanitsch R et al (2005) Technical and economical comparison of micro CHP systems. In: Proceedings of international conference on future power systems, Amsterdam, Netherlands, 18 November 2005, 6 pp

[21] Lazzarin RM, Gasparella A (1997) New ideas for energy utilisation in combined heat and power with cooling. Appl Therm Eng 5(17):479-500

[22] Hatziargyriou N, Asano H, Iranvani R et al (2007) Microgrids. IEEE Power Energy Mag 5(4):78-94

[23] United Oration Economic and Social Commission for Asia and the Pacific (1999) Guide book on cogeneration as a means of pollution control and energy efficiency in Asia, Thailand, November 1999, 35 pp

[24] Niu M, Huang W, Guo JH et al (2010) Research on economic operation of microgrid. Power Syst Technol 34(11):38-42

[25] Xu LZ, Yang GY, Xu Z et al (2011) Combined scheduling of electricity and heat in a microgrid with volatile wind power. Autom Electr Power Syst 35(9):53-60

[26] Bhuvaneswari R, Edrington CS, Cartes DA et al (2009) Online economic environmental optimization of a microgrid using an improved fast evolutionary programming technique. In: Proceedings of North American power symposium (NAPS), Florida, USA, 4-6 Oct 2009, pp 1-6

[27] Deng QJ, Gao X, Zhou H (2011) System modeling and optimization of microgrid using Genetic Algorithm. In: Proceedings of the 2nd international conference on intelligent control and information, Harbin, China, 25-28 July 2011, pp 540-544

[28] Li L (2011) Study of economic operation in microgrid. North China Electric Power University, Beijing

[29] Xi P, Li P, Liu JX (2011) Research on economic operation of microgrid. Electr Power Sci Eng 27(9):1-7

[30] Mohamed F, Koivo H (2007) System modeling and online optimal management for a microgrid with battery storage. In: Proceedings of international conference on clean electrical power, Capri, Italy, 21-23 May 2007, pp 148-153

[31] Chen SX, Gooi HB, Wang MQ (2012) Sizing of energy storage for microgrids. IEEE Trans Smart Grid 3(1):142-151

[32] Yan DW, Wei G, Chen XZ et al (2012) Microgrid energy optimization considering interruptible load. Proc CSU-EPSA 24(1):88-93

[33] Chen CS, Duan SX, Cai T (2011) Optimal allocation and economic analysis of energy storage system in microgrids. IEEE Trans Power Electron 26(10):2762-2773 
[34] Rong A, Lahdelma R (2005) An efficient linear programming model and optimization algorithm for trigeneration. Appl Energy 82(1):40-63

[35] Sakawa M, Kato K, Ushiro S (2002) Operational planning of district heating and cooling plants through genetic algorithms for mixed 0-1 linear programming. Eur $\mathrm{J}$ Oper Res 137:677-687

[36] Gupta A, Saini RP, Sharma MP (2011) Modeling of hybrid energy system Part I: problem formulation and model development. Renew Energy 36:459-465

[37] Gupta A, Saini RP, Sharma MP (2011) Modeling of hybrid energy system Part II: combined dispatch strategies and solution algorithm. Renew Energy 36:466-473

[38] Kong XQ, Wang RZ, Li Y et al (2009) Optimal operation of a micro-combined cooling, heating and power system driven by a gas engine. Energy Convers Manag 50(3):530-538

[39] Wang L, Singh C (2008) Stochastic combined heat and power dispatch based on multi-objective particle swarm optimization. Int J Electr Power 30(3):226-234

[40] Alireza S, Turaj A (2013) Decision making under uncertainty in energy systems: state of the art. Renew Sustain Energy Rev 28:376-384

[41] Keane A, Ochoa LF, Borges CLT et al (2013) State-of-the-art techniques and challenges ahead for distributed generation planning and optimization. IEEE Trans Power Syst 28(2):1493-1502

[42] Dantzig GB (2010) Linear programming under uncertainty. In: Stochastic programming, international series in operations research \& management science. Springer, New York

[43] Zhang H, Li P (2011) Chance constrained programming for optimal power flow under uncertainty. IEEE Trans Power Syst 26(4):2417-2424

[44] Azizipanah-Abarghooee R, Niknam T, Mohammad A et al (2015) Coordination of combined heat and power-thermal-wind photovoltaic units in economic load dispatch using chance constrained and jointly distributed random variables methods. Energy 79:50-67

[45] Abedini-Duki E (2012) Optimal sizing of CHP for residential complexes by two-stage stochastic programming. In: Proceedings of 17th conference on electrical power distribution networks (EPDC), Tehran, Iran, 2-3 May 2012, pp 1-5

[46] Zadeh L (1965) Fuzzy sets. Inf Control 8(3):338-353

[47] Mohammad HM, Mehdi H, Shahriar J et al (2013) An energy management system (EMS) strategy for combined heat and power (CHP) systems based on a hybrid optimization method employing fuzzy programming. Energy 49:86-101

[48] Jing YY, Bai H, Wang JJ (2012) A fuzzy multi-criteria decision making model for CCHP systems driven by different energy sources. Energy Policy 42:286-296

[49] Momoh JA, Ma XW, Tomsovic K (1995) Overview and literature survey of fuzzy set theory in power systems. IEEE Trans Power Syst 10(3):1676-1690

[50] Mavrotas G, Diakoulaki D, Florios K et al (2008) A mathematical programming framework for energy planning in services' sector buildings under uncertainty in load demand: the case of a hospital in Athens. Energy Policy 36(7):2415-2429

[51] Rommelfanger H (1996) Fuzzy linear programming and applications. Eur J Oper Res 92(3):512-527

[52] Buckley J, Qu Y (1991) Solving systems of linear fuzzy equations. Fuzzy Set Syst 43(1):33-43

[53] Piacentino A, Cardona F (2008) Eabot-energetic analysis as a basis for robust optimization of tri-generation systems by linear programming. Energy Convers Manag 49(11):3006-3016

[54] Alireza S (2012) Possibilistic-scenario model for DG impact assessment on distribution networks in an uncertain environment. IEEE Trans Power Syst 27(3):1283-1293
[55] Sahin C, Shahidehpour M, Erkmen I (2012) Generation risk assessment in volatile conditions with wind, hydro, and natural gas units. Appl Energy 96:4-11

[56] Alabdulwahab A, Abusorrah A, Zhang X et al (2015) Coordination of interdependent natural gas and electricity infrastructures for firming the variability of wind energy in stochastic day-ahead scheduling. IEEE Trans Sustain Energy 6(2):606-615

[57] Chaudry M, Jenkins N, Qadrdan M et al (2014) Combined gas and electricity network expansion planning. Appl Energy 113:1171-1187

[58] Wu JD (2010) The development of smart energy network is the cornerstone of building the new energy structure in twenty-first Century. Oriental Morning Post

[59] Wikipedia (2014) Shale gas in the United States http://en. wikipedia.org/wiki/Shale_gas_in_the_United_States\#cite_ note- 012

[60] Belderbos A, Delarue E, D'haeseleer W (2015) Possible role of power-to-gas in future energy systems. In: Proceedings of the 12th international conference on the European energy market (EEM), Lisbon, Portugal, 19-22 May 2015, pp 1-5

[61] Jing Q, Zhao YD, Jun HZ (2015) Multi-stage flexible expansion co-planning under uncertainties in a combined electricity and gas market. IEEE Trans Power Syst 30(4):2119-2129

[62] Correa-Posada CM, Sánchez-Martın P (2014) Security constrained optimal power and natural-gas flow. IEEE Trans Power Syst 29(4):1780-1787

[63] Geidl M, Andersson G (2007) Optimal power flow of multiple energy carriers. IEEE Trans Power Syst 22(1):145-155

[64] Lu LL, Liang W, Zhang LB et al (2015) A comprehensive risk evaluation method for natural gas pipelines by combining a risk matrix with a bow-tie model. J Nat Gas Sci Eng 25:124-133

[65] Moskalenko N, Lombardi P, Komarnicki P (2014) Multicriteria optimization for determining installation locations for the power-to-gas technologies. In: Proceedings of 2014 IEEE PES general meeting conference \& exposition, Washington, DC, USA, 27-31 July 2014, pp 1-5

[66] Urbina M, Li Z (2007) A combined model for analyzing the interdependency of electrical and gas systems. In: Proceedings of the IEEE 39th North American power symposium (NAPS'07), Las Cruces, NM, USA, 30 Sept-2 Oct 2007, pp 468-472

[67] Unsihuay C, Marangon-Lima J, De Souza A et al (2010) A model to long-term, multiarea, multistage, and integrated expansion planning of electricity and natural gas systems. IEEE Trans Power Syst 25(2):1154-1168

[68] Saldarriaga CA, Hincapir A, Salazar H (2013) A holistic approach for planning natural gas and electricity distribution networks. IEEE Trans Power Syst 28(4):4052-4063

[69] Unsihuay C, Marangon-Lima J, De Souza A (2007) Integrated power generation and natural gas expansion planning. In: Proceedings of IEEE PES powertech conference, Lausanne, Switzerland, 1-5 July 2007, pp 1404-1409

[70] Almassalkhi M, Hiskens I (2011) Optimization framework for the analysis of large-scale networks of energy hubs. In: Proceedings of the 17th power system computation conference (PSCC), Stockholm, Sweden, 22-26 Aug 2011, 7 pp

[71] Koeppel G, Andersson G (2009) Reliability modeling of multicarrier energy systems. Energy 34(3):235-244

[72] Krause T, Andersson G, Frohlich K et al (2011) Multiple-energy carriers: modeling of production, delivery, and consumption. Proc IEEE 99(1):15-27

[73] Kamalinia S, Wu L, Shahidehpour M (2014) Stochastic midterm coordination of hydro and natural gas flexibilities for wind energy integration. IEEE Trans Sustain Energy 5(4):1070-1079 
[74] Correa-Posada CM, Sánchez-Martın P (2013) Stochastic contingency analysis for the unit commitment with natural gas constraints. In: Proceedings of IEEE PowerTech conference, Grenoble, France, 16-20 June 2013, pp 1-6

[75] Sun GQ, Chen S, Wei ZN et al (2015) Probabilistic optimal power flow of combined natural gas and electric system considering correlation. Autom Electr Power Syst 39(21):11-17

[76] Bai LQ, Li FX, Cui HT et al (2016) Interval optimization based operating strategy for gas-electricity integrated energy systems considering demand response and wind uncertainty. Appl Energy 167:270-279

[77] Kempton W, Dhanju A (2006) Electric vehicles with V2G: storage for large-scale wind power. Windtech Int 2(1):18-21

[78] Claas B, Marker S, Blckert J et al (2010) Integration of plug-in hybrid and electric vehicles: experience from Germany. In: Proceedings of IEEE power and energy society general meeting, Minneapolis, MN, USA, 25-29 July 2010, pp 1-3

[79] Roe C, Meliopoulos AP, Meisel J et al (2008) Power system level impacts of plug-in hybrid electric vehicles using simulation data. In: Proceedings of the energy 2030 conference on energy, Atlanta, GA, USA, 17-18 Nov 2008, pp 1-6

[80] Bao Y, Jiang JC, Zhang WG et al (2012) Model and control strategy of electric vehicle mobile energy storage system. Autom Electr Power Syst 36(22):36-43

[81] Zheng Y, Dong ZY, Xu Y et al (2014) Electric vehicle battery charging/swap stations in distribution systems: comparison study and optimal planning. IEEE Trans Power Syst 29(1):221-229

[82] Liu ZP, Wen FS, Ledwich G (2013) Optimal planning of electric-vehicle charging stations in distribution systems. IEEE Trans Power Deliv 28(1):102-110

[83] Wang W, Li R, Jiang JC (2016) Key issues and research prospects of distribution system planning orienting to Energy Internet. High Volt Eng 42(7):2028-2036

[84] Ge SY, Feng L, Liu H et al (2013) Planning of charging stations considering traffic flow and capacity constraints of distribution network. Power Syst Technol 37(3):582-589

[85] Han WQ, Wang GB, Wen FS (2014) Multistage optimal planning of electric vehicle charging facilities. J North China Electric Power Univ 41(5):23-30

[86] Lin XN, Sun JW, Ai SF et al (2014) Distribution network planning integrating charging stations of electric vehicle with V2G. Int J Electr Power 63:507-512

[87] Sortomme E, Hindi MM, Macpherson SDJ et al (2011) Coordinated charging of plug-in hybrid electric vehicles to minimize distribution system losses. IEEE Trans Smart Grid 2(1):198-205

[88] Dharmakeerthi CH, Mithulananthan N, Saha TK (2015) A comprehensive planning framework for electric vehicle charging infrastructure deployment in the power grid with enhanced voltage stability. Int Trans Electr Energy 25(6):1022-1040

[89] Yao WF, Zhao JH, Wen FS et al (2014) A multi-objective collaborative planning strategy for integrated power distribution and electric vehicle charging systems. IEEE Trans Power Syst 29(4):1811-1821

[90] Ning G, White RE, Popov BN (2006) A generalized cycle life model of rechargeable Li-ion batteries. Electrochim Acta 51(10):2012-2022

[91] Nafisi H, Mohammad S, Abyaneh H et al (2016) Two-stage optimization method for energy loss minimization in microgrid based on smart power management scheme of PHEVs. IEEE Trans Smart Grid 7(3):1268-1276
[92] Zhang L, Li YY (2017) Optimal management for parking-lot electric vehicle charging by two-stage approximate dynamic programming. IEEE Trans Smart Grid 8(4):1722-1730

[93] Waqar A, Wang SR, Khalid MS et al (2015) Multi-objective chance constrained programming model for operational- planning of V2G integrated microgrid. In: Proceedings of the 5th international conference on electric utility deregulation and restructuring and power technologies (DRPT), Changsha, China, 26-29 Nov 2015, pp 443-448

[94] Liu ZX, Wu QW, Oren S et al (2016) Distribution locational marginal pricing for optimal electric vehicle charging through chance constrained mixed-integer programming. IEEE Trans Smart Grid 99:1

[95] Mirzaei MJ, Kazemi A, Homaee O (2015) A probabilistic approach to determine optimal capacity and location of electric vehicles parking lots in distribution networks. IEEE Trans Ind Inf 12(5): 1963-1972

[96] Guo S, Zhao HR (2015) Optimal site selection of electric vehicle charging station by using fuzzy TOPSIS based on sustainability perspective. Appl Energy 158(15):390-402

[97] Sarvestani AS, Safavi AA (2009) A novel optimal energy management strategy based on fuzzy logic for a hybrid electric vehicle. In: Proceedings of IEEE international conference on vehicular electronics and safety (ICVES), Pune, India, 11-12 Nov 2009, pp 141-145

[98] Hajimiragha AH, Canizares CA, Fowler MW et al (2011) A robust optimization approach for planning the transition to plug-in hybrid electric vehicles. IEEE Trans Power Syst 26(4):2264-2274

[99] Huang YN, Guo CX, Wang ZC et al (2015) Considering the electric vehicle grouping policy of user satisfaction. Autom Electr Power Syst 39(17):183-191

[100] Yun M, Yuxin B (2010) Research on the architecture and key technology of internet of things (IoT) applied on smart grid. In: Proceedings of international conference on advances in energy engineering (ICAEE), Beijing, China, 19-20 June 2010, pp 69-72

[101] Sun QY, Han RK, Zhang HG et al (2015) A multiagent-based consensus algorithm for distributed coordinated control of distributed generators in the Energy Internet. IEEE Trans Smart Grid 6(6):3006-3019

[102] Yang Z, Zhang J, Kintner-Meyer MCW et al (2011) Electrochemical energy storage for green grid. Chem Rev 111:3577-3613

[103] Raghavan B, Irwin D, Albrecht J et al (2012) An intermittent Energy Internet architecture. In: Proceedings of the third international conference on future energy systems: Where Energy, Computing and Communication Meet (e-Energy), Madrid, Spain, 9-11 May 2012, pp 1-4

[104] Zhao TF (2010) Design and control of a cascaded H-bridge converter based solid state transformer (SST). North Carolina State University, North Carolina State

[105] Tie FZ, Li YY, Jun W et al (2007) $270 \mathrm{kVA}$ solid state transformer based on $10 \mathrm{kV} \mathrm{SiC}$ power devices. In: Proceedings of IEEE Electric Ship Technologies Symposium, Arlington, VA, USA, 21-23 May 2007, pp 145-149

[106] Wang GY, She X, Wang F et al (2011) Comparisons of different control strategies for $20 \mathrm{kVA}$ solid state transformer. In: Proceedings of IEEE energy conversion congress and exposition, Phoenix, AZ, USA, 17-22 Sept 2011, pp 3173-3178

[107] Zhou D (2016) The development and cooperation organization of global Energy Internet was established. Sino-Glob Energy 21:96 
[108] Deng JL (2016) The concept and development model of Energy Internet. Electr Power Autom Equip 36(3):1-5

[109] Pu TJ, Liu KW, Chen NS et al (2015) Architecture and key technologies of urban Energy Internet based on active distribution network. Proc CSEE 35(14):3511-3521

Yijia CAO received his Ph.D. degree from Huazhong University of Science and Technology, China, in 1994. He is now the Vice President of Hunan University in China. His main research interests include the Energy Internet operation and planning, power system optimization and stability control, and smart grid information integration technology.

Qiang LI received his Bachelor degree from Hunan University, China, in 2015, where he is pursuing the Master degree. His main research interests include power system optimization and the Energy Internet.

Yi TAN received his Ph.D. degree from Hunan University, China, in 2014. He is currently a research staff at Hunan University. His main research interests include distribution network scheduling and planning, and the application of heuristic optimization and stochastic optimization in power systems.
Yong LI received his Ph.D. degree from TU Dortmund, Germany, in 2012. He is now a professor of Hunan University in China. His main research interests include power system stability analysis and control, AC/DC energy conversion systems and equipment, analysis and control of power quality, and HVDC and FACTS technologies.

Yuanyang CHEN received his Master degree from Zhejiang University, China, in 2012. He is now working at State Grid Hunan Electric Power Company, China. His main research interests include power system dispatch and security analysis.

Xia SHAO received her Ph.D. degree from Hunan University, China, in 2013. She is currently an assistant professor at Hunan University. Her main research interests include power system protection and integrated automation technology.

Yao ZOU received his Bachelor degree from Hunan University, China, in 2015, where he is pursuing the Master degree. His main research interests include operation of integrated energy system and distributed generation planning in distribution network. 